\title{
ON THE ERA OF EDUCATIONAL HYPERMEDIA COMPUTING
}

From Simple Links to More Complex Structures

\author{
Anneli Heimbürger and Jari Multisilta \\ Tampere University of Technology, Finland \\ E-mail: anneli.heimburger@tut.fi; jari.multisilta@tut.fi
}

Abstract: The paper presents a timeline of information and communication technologies in learning since the days of Vannebar Bush's Memex, Douglas Engelbart's Augment, Ted Nelson's Xanadu, and PLATO systems to the current lively research and development work going on between the traditional hypertext research community and the World Wide Web Consortium (W3C). Hypermedia has been widely applied in computer assisted instruction and learning. Engelbart's NLS/Augment can be regarded as the first CSCW (Computer Supported Collaborative Work) environment. Later, such systems as Intermedia, Microcosm and HyperCard have successfully presented the ideas of hypertext in learning contexts. In this paper we discuss the development of learning theories and hypertext linking environments and their roles in today's networked and mobile learning environments.

Keywords: Information and communication technologies; ICT; Computer assisted instruction; CAI; Computer assisted learning; CAL; Hypertext linking; History; Future trends

\section{INTRODUCTION}

"The human mind operates by association. With one item in its grasp, it snaps instantly to the next that is suggested by the association of thoughts, in accordance with some intricate web trails carried by the cells of the brain, ... the speed of action, the intricacy of trails, the detail of mental pictures, are awe-inspiring beyond all else in nature. Man cannot 
hopefully to duplicate this mental process artificially, but he certainly ought to be able to learn from it." (Bush, 1945)

Hypermedia integrates digital computing with the natural tendency of the human mind to think associatively and to manage information hierarchically. Hypermedia applications allow users to navigate collections of compound documents non-sequentially by (a) jumping backward and forward, (b) presenting an overview of the whole hyperdocument space to a user, (c) zooming in for details, (d) experiencing sequences of animation, sound or digital video, (e) reading the information at their own rate independent of place and time, and (f) learning by associations. Several research results have been published, which indicate that hypertext learning environments support interactive learning models (Burch, 2001; Crestani and Ntioudis, 2002; Harley, 2001; Hede, 2002; Mullier et al., 2002; Ohl, 2001; Oliver and McLoughlin, 2001).

Current network and mobile technologies together with World Wide Web course tools provide us with possibilities to build more and more challenging learning environments (Carlson and Repman, 2002). Even the differences between formal learning, informal learning and way of working are diminishing. Contextual access is predicted to be one of the most relevant means of retrieving information from the traditional and mobile Web; a user, a location, a device, and time determining the context.

Could it be that we, in our great enthusiasm for developing new technologies, have overlooked some pertinent pieces of knowledge which already were there before the Web: learning theories with best practices from classrooms and versatile hypertext links supporting associative thinking of human mind?

The remainder of the paper is organised as follows. A timeline of information and communication technologies in learning is presented in Section 2. The development of learning theories is discussed in Section 3. Development trends of hypertext linking are described in Section 4. Section 5 is reserved for conclusions.

\section{TIMELINE OF INFORMATION AND COMMUNICATION TECHNOLOGIES IN LEARNING}

Information and communication technologies (ICT) in learning, for example computer assisted instruction (CAI), computer aided learning (CAL) and hypermedia, have developed hand in hand with technological progress in computer science and information systems. In historical timeline 
of these technologies, five generations of mainstream computing environments can be identified (Table 1):

Table 1. Timeline of ICT in learning.

$\underline{\text { Year }} \quad \underline{\text { Event }}$

$I^{\text {st }}$ Generation: Time of microfiches and mainframes

1945 Vannevar Bush proposed the Memex system, a microfichebased system of documents and links, in his article entitled "As we may think". Memex foreshadowed the advent of hypertext. Fast access of information, ability to annotate, ability to link and to store trails of links were some requirements for the Memex specified by Bush. (Bush, 1945)

1960s Several CAI projects started. Stanford project and the Programmed Learning and Teaching Operation (PLATO) system were influential CAI projects with heavy emphasis on educational research (Nievergelt, 1980; Pantages, 1976).

1962 Douglas Engelbart published a paper "Augmenting human intellect: A conceptual framework". Engelbart defined the functions necessary for computers to augment human abilities such as links between texts, electronic mail, screens with multiple windows, and facilities for collaborative work. Engelbart invented the mouse, outliner and idea processor, and on-line help systems integrated with software. Engelbart's NLS/Augment can be regarded as the first environment for Computer Supported Collaborative Work (CSCW). (Engelbart, 1963)

1965 Theodor Holm Nelson invented the term "hypertext" and presented it to the world. Ever since Nelson has continued his mission in life as universally acknowledged ideologist of hypertext. Xanadu and ZigZag are the two hypertext engines designed by Ted Nelson. (Nelson, 1987; Nelson, 2004)

1968-1988 Andries Van Dam and his team at Brown University (USA) developed the Hypertext Editing System and its extension File Retrieval and Editing Systems (FRESS). According to Van Dam, FRESS was the first system to have an undo function. The third and, nowadays the very classic, hypertext system developed by Van Dam and his group was called 
Intermedia. Intermedia-based applications were used in teaching and learning biology and English literature at Brown University. Professors prepared their lessons and course materials and students created their reports. One of the remarkable ideas of Van Dam was the "web", a set of links that belongs together. This makes it possible for different users to create sets of links of their own on the same document. In present hypertext terminology these sets of links are called linkbases. (Berk \& Devlin, 1991; Yankelovich et al., 1985; Van Dam, 1988)

1970s Mitre Corporation has a large-scale CAI project, Ticcit, for production of courseware on an industrial basis. Problem solving environments such as the Logo project and Smalltalk system have influenced many people. (Nievergelt, 1980)

\section{$2^{\text {nd }}$ Generation: Time of workstations}

1972-1983 According to Frank Halasz, ZOG, developed at CarnegieMellon University was the last first generation hypertext systems, which all run on mainframes. The second generation of hypertext authoring products, such as Intermedia and KMS, was born in the beginning of 1980s with the development of workstations. Faster computers, displays and networks supported more versatile user interfaces and collaborative work, for example within designers and engineers sharing the same KMS-based applications like technical documents on a computer network. (Berk \& Devlin, 1991)

\section{$3^{\text {rd }}$ Generation: Time of personal computers began}

Peter Brown invented Guide, the first commercial hypertext authoring system for personal computers. Guide was first available for Apple MacIntosh and in 1987 for IBM PC. There was less functionality than in mainframe and workstation-based products but graphical user interface and the possibility for link typing were new features.

1986 Xerox Palo Alto Research Center released NoteCards. NoteCards, KMS and Intermedia supported graphics and animation nodes. They also supported creation of graphical overviews of the structure of the hyperdocument. The 
overviews made it easier for users to navigate and decreased the cognitive overload followed by the "lost in hyperspace" phenomenon. (Halasz, 1988)

1986 ISO published the Standard Generalized Markup Language (SGML) which is the very basis for structured document and link management in today's Web (ISO 8879).

1987 HyperCard for Apple Macintosh was released. The metaphor of HyperCard is based on cards which form stacks. Cards are linked to other cards with link anchors called buttons. The IBM PC version of Hyperties developed at University of Maryland was introduced. Hyperties used the metaphor of an electronic book or encyclopaedia.

1989 Tim Berners-Lee proposed a distributed hypertext system for the management of general information at CERN (Berners-Lee, 1999).

1990s Usability of hypermedia systems began to be a serious matter of interest. Many usability laboratories were established around the world. Jacob Nielsen has published books under the titles Usability engineering and later Designing Web usability (Nielsen, 1993; Nielsen, 2000).

\section{$4^{\text {th }}$ Generation: Era of the World Wide Web $(W W W)$ started}

In November Tim Berners-Lee has programmed a pointand-click browser/editor that he called WorldWideWeb. On Christmas Day 1990 WorldWideWeb browser/editor was working on Berners-Lee's and his colleague Robert Cailliau's machines, communicating over Internet with the info.cern.ch -server. (Berners-Lee, 1999)

1993 In February, NCSA made the first version of Mosaic browser available over the Web (Berners-Lee, 1999).

1994 In April, Netscape released the commercialized version of the Mosaic (Berners-Lee, 1999).

1996 Microsoft's Internet Explorer was released (Berners-Lee, 1999).

1995- Open hypermedia research community indicated that the solution to many hypertext link management issues is to separate links from content. Several open hypermedia systems were implemented. Chimera, Hyper-G and Microcosm are examples of the classics, where support for non-embedded links inside and between WWW pages has 
been developed (Carr et al., 1995; Grønbæk and Trigg, 1999).

1996 Jari Multisilta at Tampere University of Technology has designed, implemented and evaluated a Hypermedia based Learning Environment (HMLE) for mathematics. Automatic link generation is one example of the HMLE's advanced functionalities. HMLE based Matrix Algebra I was one of the first complete courses implemented in World Wide Web. (Multisilta, 1996)

1997 ISO published a standard Hypermedia/Time-based Structuring Language (HyTime) (ISO/IEC 10744). HyTime as such was too complicated and abstract for commercial products. Later, parts of the standard have been adopted to XML Linking Language and to some commercial advanced browsers for creating customized applications.

1998 In February, the eXtensible Markup Language (XML) got the recommendation status in the W3C. XML is a subset of SGML and especially designed for Web (W3C, 2004a)

2001

In June, XML Linking Language (XLink) specification got the recommendation status in the W3C. XLink defines extended links with multiple linking and linkbase facilities and as such brings the possibility to implement more versatile link structures, already defined in earlier days' hypermedia systems such as Intermedia, on the Web. XLink is increasingly moving the Web towards an open hypermedia approach. However, XLink is quite sophisticated and is applied mainly in customized applications. DocZilla by Citec Information Inc. is an example of commercial browser/editor supporting multiended links and linkbases (W3C, 2004d; DocZilla, 2004).

2001- Peter Brusilovsky presented a two-level categorization for adaptive systems: adaptation to user's behaviour and adaptation to the client device. Brusilovsky and his research group at Carnegie Mellon University and nowadays at University of Pittsburgh are developing methods for adaptive Web. (Brusilovsky et al., 2002)

\section{$5^{\text {th }}$ Generation: Mobile Web and Semantic Web are developing}

Tim Berners-Lee defined the next generation of the Web, which he calls the Semantic Web. W3C's Semantic Web -activity aims to develop Web technologies to have data 
defined and linked in a way that allows it to be used by machines, not just for display purposes, but for integration and reuse of information across various applications. (Berners-Lee et al., 2001)

2001 The Oxford Internet Institute (OII) was founded (OII, 2004). OII aims to become the world's leading multi-disciplinary academic centre focused on furthering understanding of the economic, political, institutional, scientific, legal and other social factors shaping the Internet and its implications for society.

2002- Mobile Internet starts to provide new means for working and learning. Harri Ketamo at Tampere University of Technology, Pori, has developed and evaluated xTask environment for user and platform adaptation in Web-based learning environments. (Ketamo, 2002)

2002- XLink becomes a bridge between open hypermedia research and $\mathrm{W} 3 \mathrm{C}$ communities. Both communities have a great potential to learn from each other. On the one hand, hypermedia research community begins to use the Web and XLink as a test bed for developing and evaluating more complex link structures. On the other hand, W3C community could utilize even more efficiently the hypermedia research work already done. XLink extensions such as support for multimedia synchronization, mapping between open hypermedia interchange format and an XLink linkbase, and time-sensitive linking mechanisms are published. (Heimbürger, 2004; Grønbæk et al., 2000; Muchaluat-Saade et al., 2002)

2004 In February, the Semantic Web technologies got the recommendation status in the $\mathrm{W} 3 \mathrm{C}$ (W3C, 2004b).

2004 The mobile computing has two different starting points. The first is the computer manufacturers. One of the first developers for mobile devices has been Psion (Organiser since 1984) and Apple Computer (Newton, 1993). These devices did not have any communications capabilities. They were more like electronic calendars although it was possible to draw and write with the Newton. The second starting point is mobile communication device manufacturers. In 1996 Nokia introduced the world's first all-in-one communicator, the Nokia 9000. It had many features seen in PDAs in addition to the GSM communications capabilities. Today also the PDAs have an integrated communication 
technologies (such as GSM, GPRS or WLAN). This year (2004) Nokia have introduced its newest Communicator with both WLAN and GSM/GPRS interfaces.

Future Openness of computer and information systems, automatic integration and reuse of information across various applications and devices, possibilities for cultural localization, context awareness with content personalization and adaptation, multimodal interfaces and facilities for authoring and managing versatile link structures are some of the most important challenges for the network of the future.

From the chronology we can see that information and communication technologies have been used in learning applications in many ways. Almost every new technology is to be applied in learning context. For example, HyperCard became very popular among schools soon after it was published. The students could easily do their presentations and group work using Macintosh and HyperCard. The popularity of HyperCard was based mainly on two things: first, it was free software included for every Macintosh and second, it was very easy to program. These two principles characterize also the World Wide Web. Today, many features included in commercial learning environments and learning platforms have already been present for example in Augment, PLATO, Intermedia and Guide. From this point of view the mobility and Semantic Web are new paradigms - a great deal of research and experiments are needed in order to launch the full potential of these technologies in learning.

Next we will focus on how our understanding of learning has changed over time.

\section{DEVELOPMENT OF LEARNING THEORIES}

In the previous section we presented a timeline of several technologies that have influenced CAL. How the human mind learns is still an open research issue that has been studied from many perspectives. In this chapter we present a simplified timeline that describes the development of learning theories during the last century.

The learning theories can be described with a line segment with two ends. On one end there is behaviourist learning model and on the other end there is cognitive learning model (i.e. constructivist learning model). In between, there are numerous learning models mixing features of behaviourism and constructivism. The line represents also a simplified 
timeline in such that behaviourist learning models were commonly accepted in the beginning of 1900 and the constructive learning models are much newer ideas. One of the developers of behaviourism was B. F. Skinner (Graham, 2002). In general, behaviourism says that our learning is based on stimulus response method which means that by certain stimulus there should be a certain response. One example of behaviourist learning is learning by memorizing things by heart. In computer software behaviourist programs were often of drill type: the student had to answer to a series of questions computer asked often in quick pace.

In contrast, cognitive learning model concerns more on the learning process itself. One of the first cognitive scientists has been Noam Chomsky (Thagard, 2002). It is widely accepted that networked learning should be based on cognitive learning model. An example of this in CAL could be simulation software where the student learns by studying the simulator and by experimenting with the controls of the simulation.

In the end of 1980s a new design method for CAL were launched. Crossley's and Green's (1985, 1987) method for designing lessonware were applied to many CAL developed at that time. It introduced an "open market place" where the learner could "walk" and go to small "shops" to learn. The learner could control the learning pace and route. There were also other design methods for lessonware that were based on cognitive learning model. It can be said that the use of these design methods had positive impact on the quality of learning software.

All these methods were forgotten (at least for a while) when World Wide Web appeared. Suddenly teachers started to design HTML-pages for learning purposes. The structure of the HTML-pages was not designed from pedagogical point of view. Instead, the new technology was used to publish lecture notes on the Web.

Nowadays quite a great deal of research is looking at collaborative learning. Learning is not seen only as an individual process. Learning is based on collaboration and communication. One example of this is networked learning environments that support bulletin boards and online conferencing.

When designing and studying new technologies, for example linking methods, we should keep the lessons learned in mind and try to focus on pedagogically new and meaningful ideas of applying new technologies. We should also remember the associative nature of human thinking. 


\section{HYPERTEXT LINKING: MEANS FOR IMPLEMENTING ASSOCIATIVE INFORMATION STRUCTURES}

\subsection{Extended links}

Hypertext is a tool for building and using associative information structures. Pieces of knowledge can be assembled in different ways according to different perspectives of users. Hypertext links are implementations of relationships within and among sets of data. In fact, links are themselves important pieces of data that need to be authored, stored, maintained, delivered and used just like other data. Many earlier hypertext systems had a versatile linking structure. For example, the Intermedia system had structured links with attributes such as types and keywords (Yankelovich et al., 1985). Links in Intermedia were bi-directional and it was possible to get an overview of the link structure in a hypertext document. Intermedia also included the concept of a linkbase. These features are still not widely found on the Web. The linking mechanism on the Web is still weak, although there are strengths in the HTML linking. HTML has an easy syntax and it is simple to implement. However, the design of Web pages has concentrated rather on getting the right look than to constructing useful structures.

Hypertext link management has been a matter of serious concern in the open hypermedia $(\mathrm{OH})$ research community for over ten years now. When links are embedded in documents, as they are now in the Web, there are several disadvantages which affect the management effort of contents and their relations. Open hypermedia research and the recent XML Linking Language (XLink) recommendation in the W3C indicate that the solution is to separate the links from the content by means of an external hypermedia linkbase architecture. In addition to linkbases, XLink defines semantic, behaviour and traversal link attributes, and multi-ended links (Figure 1).

XLink's extended link can include attributes reflecting the relationships between the starting and ending resources of a link. Examples are user id, place, time and information type. Multi-ended links can also contain multiended links, which makes multiple link networks possible. Some of these features already existed in early days' stand-alone hypertext systems. XLink attempts to adjust these linking facilities to the Web. 


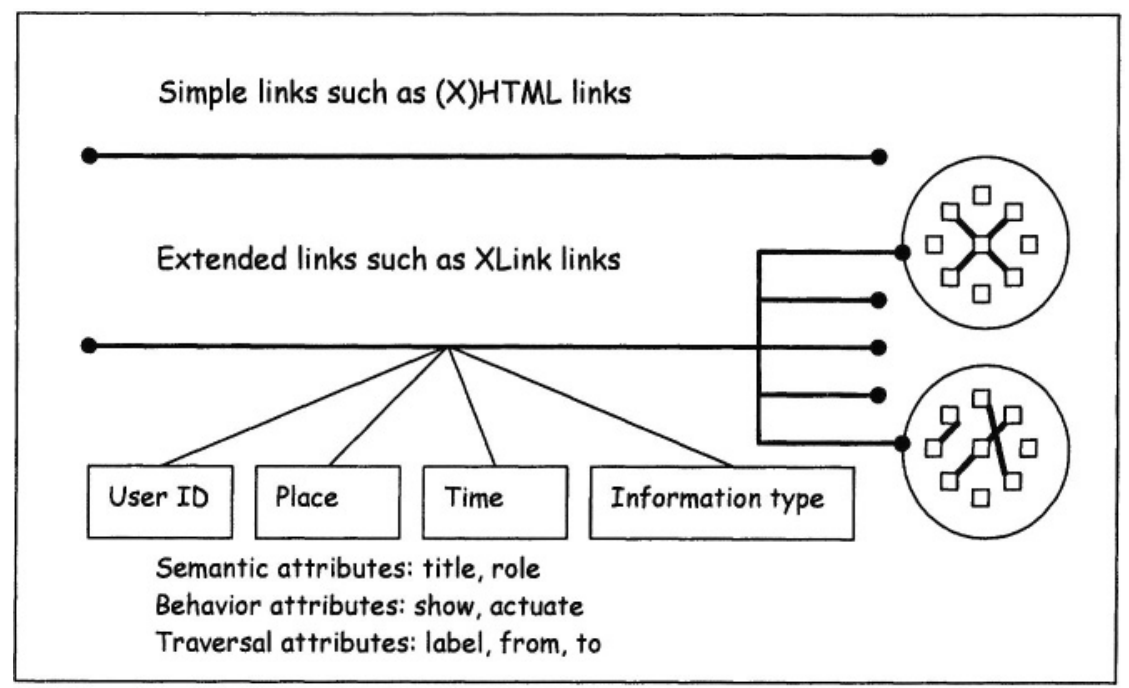

Figure 1. A HTML link versus an XLink link.

\subsection{Examples of applying extended link structures to the design of training materials}

If the links are kept separate from the contents, more flexibility and control is achieved, such as (a) contents and fragments of contents can be linked automatically without changing them in any way, (b) alternative sets of links can be associated with the same content according to the needs of different contexts, (c) collections of links can be filtered on demand and (d) link integrity can be verified automatically.

The linkbase architecture allows collaborative annotation, for example the common set of learning materials on the Web (W3C, 2004c). Linkbase architecture also enables the creation of more complex link structures such as combinations of multi-ended links and linkbases, and thus is necessary from a link management point of view. Versatile link structures can be applied to contextual composing, delivering and using assemblies of training materials on the Web. Examples of possible applications are: (a) composing step-by-step instructions in industrial training situations onsite, for example in simulated trouble-shooting situations, (b) providing different views to training materials for example chronological, cultural and environmental views, (c) a possibility to switch between a novice-, an intermediate- or an expert-view depending on the user's level of know-how, (d) time-based teaching of history, historical events and relations between them, (e) semantic relations to topics, for instance the topic "the Finnish composer 
Jean Sibelius" in music teaching can be an anchor to a four-ended link: events, persons, places, sample library of compositions, (e) multilingual and multicultural aspects of applications, and (f) curricula of universities and students' study programs.

Hypertext linking has developed from simple to versatile linking in stand-alone systems, back to simple links in the Web, and now proceeding again towards more complex link structures. First implementations are to be in extranet and intranet environments that are subsets of the Web. XLink and alike languages are enriching linking methods and tools for constructing associative information structures. They are also developing the Web towards a world wide open hypermedia system.

\section{CONCLUSIONS}

The human mind seems to be associative by its nature. This has been observed in many contexts and has been formulated in network models of human memory (Parsaye et al., 1989). The natural tendency of human mind to build complex associative structures differs from the linear way in which information is generally organized and presented, for example in books. Hypertext offers us a tool for building and using associative information structures.

It must be remembered that learning happens inside our brain - this process can be aided using technologies. However, the nature of learning is in thinking and doing. Thinking is an associative process and it can be expressed in computer by using hypermedia links that encompass the rich semantics of relationships of different things. When designing and studying new technologies, in this case especially linking methods, we should keep the lessons learned in mind and try to focus on pedagogically new and meaningful ideas of applying new technologies.

\section{REFERENCES}

Berk, E. and Devlin, J. (eds.), 1991. Hypertext/hypermedia handbook. New York: Intertext Publications. 583 p.

Berners-Lee, T., 1999. Weaving the Web. The original design and ultimate destiny of the World Wide Web. New York, Harper San Francisco. 226 p.

Berners-Lee, T., Hendler, J. and Lassila, O., 2001. The Semantic Web. Scientific American, Vol. 284, No. 5, pp. $28-37$.

Brusilovsky, P., Stock, O. and Strapparava, C. (eds.), 2002. Adaptive hypermedia and adaptive Web-based systems. Lecture Notes in Computer Science 1892, Berlin, SpringerVerlag. $422 \mathrm{p}$. 
Burch, R. O., 2001. Effective web design and core communication issues: The missing components in Web-based distance education. Journal of Educational Multimedia and Hypermedia, Vol. 10, No. 4, pp. 357 - 367.

Bush, V., 1945. As we may think. Atlantic Monthly, Vol. 176, No. 1, pp. $101-108$.

Carlson, R. D. and Repman, J., 2002. Activating Web-based e-learning. International Journal on E-learning, Vol. 1, No. 2, pp. 7-10.

Carr, L. et al., 1995. The distributed link service: A tool for publishers, authors and readers. In: The $4^{\text {th }}$ International World Wide Web Conference: The Web Revolution, Boston, MA, O'Reilly. Pp. 647 - 656.

Crestani, F. and Ntioudis, S. P., 2002. User centered evaluation of an automatically constructed Hyper-TextBook. Journal of Educational Multimedia and Hypermedia, Vol. 11, No. 1, pp. 3-19.

Crossley, K. and Green, L., 1985. A Practical Guide For Teachers: Designing Computer Lessonware, Canada.

Crossley K. and Green L., 1987. Lessonware. Käytännön opas opetusohjelmien laatimiseen. WSOY. Juva. (In Finnish)

DocZilla, 2004. DocZilla, [referenced 1.3.2004], <URL: http://www.doczilla.com/>.

Engelbart, D. C., 1963. A conceptual framework for the augmentation of man's intellect.In: Howerton, P. W. and Weeks, D. C. (eds.). Vistas in information handling. Volume 1. The augmentation of man's intellect by machine. Washington, D.C., Spartan Books. Pp. 1 - 29.

Graham, G., 2002. Behaviorism, The Stanford Encyclopedia of Philosophy (Fall 2002 Edition), Edward N. Zalta (ed.), [referenced 1.3.2004], <URL: http://plato.stanford.edu/archives/fall2002/entries/behaviorism/>

Grønbaek,K. and Trigg, R. H., 1999. From Web to workplace: Designing open hypermedia systems. Boston, MA, The MIT Press Books. 424 pp.

Grønbæk, K., Sloth, L. and Bouvin, N. O., 2000. Open hypermedia as user controlled meta data for the web. In Proceedings of the $\mathbf{9}^{\text {th }}$ International World Wide Web Conference, May 2000, Amsterdam, Holland. Pp. 553 - 566.

Halasz, F., 1988. Reflections on Note Cards: seven issues for the next generation of hypermedia systems. Communications of the ACM, Vol. 31, No. 7, pp. 836 - 852.

Harley, K., 2001. Learning strategies and hypermedia instruction. Journal of Educational Multimedia and Hypermedia, Vol. 10, No. 3, pp. 285 - 305.

Hede, A., 2002. An integrated model of multimedia effects on learning. Journal of Educational Multimedia and Hypermedia, Vol. 11, No. 2, pp. 177 - 191.

Heimbürger, A., 2004. Time-sensitive relationship management in technical manuals. Case: Maintenance schedules. Submitted to: The $14^{\text {th }}$ European-Japanese Conference on Information Modelling and Knowledge Bases (EJC 2004), May 31 - June 4, 2003, Skoevde University, Sweden. 20 p.

Hobbs, D. L., 2002. A constructivist approach to Web course design: A review of the literature. International Journal on E-Learning, Vol. 1, No. 2, pp. 60 - 65.

ISO 8879., 1986. Information processing - Text and office systems - Standard generalized markup language (SGML). Geneva: International Organization for Standardization. 155 p.

ISO/IEC 10744., 1997. Information processing - Hypermedia/Time-based Structuring Language (HyTime) - 2d edition [referred 1.3.2004] <URL: http://www.ornl.gov/sgml/wg8/docs/n1920//>.

Ketamo, H., 2002. User and platform adaptation in web-based learning environments. Tampere University of Technology Publications 381, Tampere, Tampere University of Technology. 142 p. 
Muchaluat-Saade, D. C., Rodrigues, R. F. and Soares, L. F. G., 2002. XConnector: Extending XLink to provide multimedia synchronization. Document Engineering (DocEng '02), November 8-9, 2002; McLean, Virginia; USA. Pp. 49 - 56.

Mullier, D., Hobbs, D. and Moore, D., 2002. Identifying and using hypermedia browsing patterns. Journal of Educational Multimedia and Hypermedia, Vol. 11, No. 1, pp. 31 - 50.

Multisilta, J., 1996. Hypermedia learning environmentfor mathematics. Tampere University of Technology Publications 183, Tampere, Tampere University of Technology. $221 \mathrm{p}$.

Nelson, T. H., 1987. Literary Machines. Edition 87.1, San Antonio, TX, Project Xanadu. 263 P.

Nelson, T. H., 2004. Home Page of Ted Nelson, [referenced 1.3.2004], <URL: http://www.xanadu.com.au/ted/>

Nielsen, J., 1993. Usability engineering. San Francisco, CA, Morgan Kaufmann Publishers, Inc. 362 p.

Nielsen, J., 2000. Designing Web usability. Indianapolis, IN, New Readers Publishing. 419 p.

Nievergelt, J., 1980. A pragmatic introduction to courseware design. IEEE Computer, Vol. 13, No. 9, pp. 7-21.

Ohl, T. M., 2001. An interaction-centric learning model. Journal of Educational Multimedia and Hypermedia, Vol. 10, No. 4, pp. 311 - 332.

OII, 2004. Oxford Internet Institute, [referenced 1.3.2004], <URL: http://www.oii.ox.ac.uk/about/>

Oliver, R. and McLoughlin, C., 2001. Exploring the practise and development of generic skills through Web-based learning. Journal of Educational Multimedia and Hypermedia, Vol. 10, No. 3, pp. 207-225.

Pantages, A., 1976. Control Data's education offering: "Plato would have enjoyed PLATO". Datamation, Vol. 22, No. 5, pp. 183 - 187.

Parsaye, K. et al., 1989. Intelligent databases. New York, NY, John Wiley \& Sons, Inc. 479 P.

Thagard, P., 2002. Cognitive Science, The Stanford Encyclopedia of Philosophy (Winter 2002 Edition), Edward N. Zalta (ed.), [referenced 1.3.2004], <URL: http://plato.stanford.edu/archives/win2002/entries/cognitive-science/>

Van Dam, A., 1988 Hypertext '87 Keynote Address, Special issue: Hypertext. Communications of the ACM, Vol. 31, No. 7, pp. 887 - 895 .

W3C, 2004a. Extensible Markup Language (XML), [referenced 1.3.2004], <URL: http://www.w3.org/XML/>

W3C, 2004b. Semantic Web, [referenced 1.3.2004], <URL: http://www.w3.org/2001/sw/>

W3C, 2004c. The Annotea Project, [referenced 1.3.2004], <URL: http://www.w3.org/2001/Annotea/>

W3C, 2004d. XML Linking Language (XLink), [referenced 1.3.2004], <URL: http://www.w3.org/TR/xlink/>

Yankelovich, N. et al., 1985. Reading and writing the electronic book. IEEE Computer, Vol. 18, No. 10, pp. 15-30. 